\title{
Estimating the burden of lung cancer in Canada attributed to occupational radon exposure using a novel exposure assessment method
}

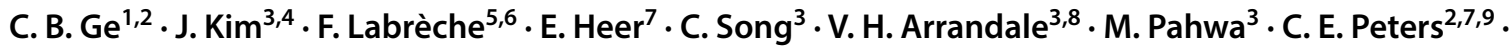 \\ P. A. Demers ${ }^{3,8}$
}

Received: 27 September 2019 / Accepted: 16 March 2020 / Published online: 30 March 2020

(c) The Author(s) 2020

\begin{abstract}
Objective Exposure to radon causes lung cancer. The scope and impact of exposure among Canadian workers have not been assessed. Our study estimated occupational radon exposure in Canada and its associated lung cancer burden.

Methods Exposed workers were identified among the working population during the risk exposure period (1961-2001) using data from the Canadian Census and Labour Force Survey. Exposure levels were assigned based on 12,865 workplace radon measurements for indoor workers and assumed to be $1800 \mathrm{mg} / \mathrm{m}^{3}$ for underground workers. Lung cancer risks were calculated using the Biological Effects of Ionizing Radiation (BEIR) VI exposure-age-concentration model. Population attributable fractions were calculated with Levin's equation and applied to 2011 Canadian lung cancer statistics.

Results Approximately 15.5 million Canadian workers were exposed to radon during the risk exposure period. $79 \%$ of exposed workers were exposed to radon levels $<50 \mathrm{~Bq} / \mathrm{m}^{3}$ and $4.8 \%$ were exposed to levels $>150 \mathrm{~Bq} / \mathrm{m}^{3}$. We estimated that $0.8 \%$ of lung cancers in Canada were attributable to occupational radon exposure, corresponding to approximately 188 incident lung cancers in 2011.

Conclusions The lung cancer burden associated with occupational radon exposure in Canada is small, with the greatest burden occurring among those exposed to low levels of radon.
\end{abstract}

Keywords Lung cancer $\cdot$ Radon $\cdot$ Occupational exposure $\cdot$ Disease burden

\section{Introduction}

Radon is a radioactive gas that is naturally created by the decay of uranium in rocks and soil (National Toxicology Program 2015). Inhalation of radon and its radioactive decay progenies (hereafter: radon) damages the lung

\section{B. Ge}

c.b.ge@uu.nl

1 Institute for Risk Assessment Sciences (IRAS), Utrecht University, Yalelaan 2, 3584 CM Utrecht, Netherlands

2 CAREX Canada, Simon Fraser University, Burnaby, Canada

3 Occupational Cancer Research Centre, Cancer Care Ontario, Toronto, Canada

4 Department of Epidemiology, Biostatistics and Occupational Health, McGill University, Montréal, Canada

5 Institut de Recherche Robert-Sauvé en santé Et en sécurité du Travail, Montréal, Canada tissue and can lead to malignancy (Agency for Toxic Substances and Disease Registry (ATSDR) 2012). In outdoor air, radon is diluted in combination with other gases in the atmosphere but, when occurring indoors, it can accumulate to higher levels. Radon is heavier than air, so levels of radon in confined or underground spaces are often elevated

6 Department of Environmental and Occupational Health, School of Public Health, Université de Montréal, Montréal, Canada

7 Department of Cancer Epidemiology and Prevention Research, Alberta Health Services, Calgary, Canada

8 Dalla Lana School of Public Health, University of Toronto, Toronto, Canada

9 Cumming School of Medicine, University of Calgary, Calgary, Canada 
compared to outdoor air (Bissett and McLaughlin 2010). Studies of underground miners in the 1920s revealed that exposure to radon as the first known cause of lung cancer and, in 1988, the International Agency for Research on Cancer (IARC) classified radon as a Group 1 carcinogen (carcinogenic to humans) with an established link to lung cancer (IARC Working Group on the Evaluation of Carcinogenic Risks to Humans 2009). After cigarette smoking, radon exposure is generally considered the most important risk factor for lung cancer and is the leading cause of lung cancer among never-smokers (Torres-Duran et al. 2014; World Health Organization 2009).

Residential radon exposure has been relatively wellcharacterized in Canada (Al-Arydah 2017; Gogna et al. 2019; Stanley et al. 2017), but occupational exposure levels, as well as the burden of cancer due to occupational exposure, is not as well understood in the Canadian context (Chen and Ford 2017). Reports of excess lung cancer mortality among uranium miners in the Northwest Territories during the 1980s and 1990 (Howe et al. 1986, 1987; Howe and Stager 1996) helped to prompt regulation of radon in high-exposure workplaces, such as mines. Radon exposure and associated lung cancer risk among workers in indoor workplaces have received considerably less attention, even though levels in these occupations can be sufficiently high to increase lung cancer risk (Marsh et al. 2017).

Previously reported estimates of the lung cancer burden associated with occupational radon exposure are typically calculated as a proportion of residential radon attributable lung cancers. For instance, Steenland et al. (2003) estimated that 2000 lung cancers annually (1.3\%) in the United States are attributable to occupational radon exposure, based on a relative lifetime dose and, therefore, a burden of $20 \%$ compared to residential radon exposure (Samet 1989). More recently, Brown et al. (Brown et al. $2012 b)$ estimated that $0.28-0.84 \%$ ( $0.56 \%$, on average) of lung cancer deaths in the United Kingdom are caused by occupational radon exposure. Again, these figures were calculated as a proportion of the total annual radon-related lung cancer deaths (NRPB 2000). There is a need to estimate cancer burden attributed to occupational radon exposure in other jurisdictions using more detailed exposure estimates, thereby addressing important gaps in both the disease burden and exposure science literature.

The objective of the present study is to estimate the percentage of lung cancers in Canada attributed to occupational radon exposure using a novel approach to assess radon exposure for workers in underground and indoor workplaces, in addition to the traditionally highly-exposed occupations. The research presented here is part of the Burden of Occupational Cancer in Canada Study (Labreche et al. 2019).

\section{Methods}

\section{Overall approach}

The overall method used to estimate the fraction of lung cancers attributed to occupational radon exposure was similar to the method used to estimate occupational cancer burden from diesel engine exhaust exposure and other exposures in the same study (Kim et al. 2018; Labreche et al. 2019). In brief, the number of incident lung cancer cases attributed to occupational radon exposure was calculated as the product of the Population Attributable Fraction (PAF) and the number of incident lung cancers in Canadians aged 25 years or older in 2011 (Statistics Canada). Levin's Equation $[\mathrm{PAF}=\operatorname{PrE}(\mathrm{RR}-1) /(1+\operatorname{PrE}(\mathrm{RR}-1))]$ was used to calculate the PAF, where PrE equals the proportion of workers ever exposed and RR is the relative risk of lung cancer associated with radon exposure derived from the Biological Effects of Ionizing Radiation (BEIR) VI exposure-age-concentration risk model (National Research Council (US) Committee on Health Risks of Exposure to Radon 1999). Results from CAREX Canada's radon exposure assessment, along with historical data from the Canadian Census and Labour Force Survey were used to estimate the total number of exposed Canadian workers during the risk exposure period (REP), defined as 1961-2001 assuming a latency of 10-50 years prior to lung cancer diagnosis. For the PAFs, 95\% confidence intervals were calculated using Monte Carlo simulation of the PrE and the RR, described in detail elsewhere (Kim et al. 2018; Labreche et al. 2019). Our work received an ethics exemption from the University of Toronto Research Ethics Board and was performed in accordance with the ethical standards as laid down in the 1964 Declaration of Helsinki and its later amendments.

\section{Exposure assessment}

Radon exposure assessment was performed as part of the CAREX Canada project (Peters et al. 2015). Briefly, exposure was assessed on the population reported in the 2006 Canadian census, where information for the Canadian workforce was available by sex, province, industry, and occupation. Exposure to radon was estimated for Canadian workers in two distinct exposure scenarios: high-risk occupations where workers have the potential for high exposure $\left(>800 \mathrm{~Bq} / \mathrm{m}^{3}\right)$ in underground/confined workspaces, and low-risk occupations where workers are exposed to radon in indoor air at lower levels $\left(>0\right.$ to $\left.>800 \mathrm{~Bq} / \mathrm{m}^{3}\right)$. For the high-risk occupations, two authors (CG, CP) identified occupations and industries with potential for high 
radon concentrations using information from the Canadian National Dose Registry (that contains doses experienced by radiation-exposed workers) (Health Canada 2019), published literature (Navaranjan et al. 2016), and government reports/grey literature (Beaugrand and Sutton 2012; Brown et al. 2012a; Canadian Broadcast Corporation 2014; Kalinowski 2014; U.S. Department of Health and Human Services 1987). They then estimated the proportion exposed in each detailed occupation and industry intersection.

For the estimation of the number of indoor workers exposed to radon, workers in indoor working environments where radon has the potential to accumulate were identified by occupation and industry by two authors (CP, PD). Distributions of radon concentrations were calculated, by province, with radon measurements from the Canadian Federal Building Survey, where 12,865 indoor federal workplaces had been monitored at the time of estimation (Health Canada 2014; Whyte et al. 2019). The data from this survey of federal buildings were used to model lognormal exposure distributions for workplace radon. From each province-specific radon exposure distribution, the proportion of workers exposed to specific ranges of radon were calculated $(>50-100,>100-150,>150-200,>200-400,>400$ 800 , and $>800 \mathrm{~Bq} / \mathrm{m}^{3}$ ). For subsequent calculation of lung cancer relative risks, the midpoints of these exposure ranges were assigned as the average radon concentrations for the exposure groups. For the unbounded category of $>800 \mathrm{~Bq} /$ $\mathrm{m}^{3}$, the province-specific mean of the radon measurements exceeding $800 \mathrm{~Bq} / \mathrm{m}^{3}$ in the federal building survey was assigned. For high-risk workers, we approximated the average of the unbounded exposure category $\left(>800 \mathrm{~Bq} / \mathrm{m}^{3}\right)$ to be $9 / 4$ times the value of the lower bound; therefore, the average radon exposure level estimated for these high-risk workers is $800 \mathrm{~Bq} / \mathrm{m}^{3} \times 9 / 4=1800 \mathrm{~Bq} / \mathrm{m}^{3}$.

\section{Calculation of ever-exposed population}

Methods for population modeling are described in detail elsewhere (Kim et al. 2018; Labreche et al. 2019). Briefly, historical workforce data were obtained from Canadian census data from 1961, 1971, 1981, 1991, and 2001. Workforce data for between-census years were linearly interpolated. To avoid double-counting workers, after 1961, only new hires were added to the working population model. New hire information was available from the Canadian Labour Force Survey by sex, industry, and age group (Statistics Canada 1976-2003). Annual workforce data in the REP (1961-2001) were merged, by industry and occupation, to aforementioned exposure assessment results to obtain the total number of workers ever exposed, by sex, province, industry, and occupation. The population was further adjusted for the probability of survival to the target year
(2011), which was estimated using Canadian life tables (Statistics Canada Demography Division 1960-2002). The reference population was the population aged 25 years and older reported in the 2011 Canadian census, which included persons alive in 2011 who were ever of working age during the REP.

\section{Relative risk of lung cancer}

The BEIR VI exposure-age concentration model (National Research Council (US) Committee on Health Risks of Exposure to Radon 1999) was used to derive relative risks of lung cancer for radon exposure. When the rate of exposure is less than 0.5 working levels $(0.5$ working levels $=85$ working level months (WLM) $=5$ millisieverts) as is the case in occupational exposure scenarios, the BEIR VI model may be represented as $R R=1+0.0768 \mathrm{w}^{*} \Phi$, where $\mathrm{w}$ is the cumulative exposure (in WLM) weighted based on timesince exposure factors $(5-14$ years $=1 ; 15-24$ years $=0.78$; $25+$ years $=0.51)$ and $\Phi$ is a factor accounting for age at the time of risk estimation $(<55$ years $=1 ; 55-64$ years $=0.57$; $65-74$ years $=0.29 ; 75+$ years $=0.09$ ). Conversion from $800 \mathrm{~Bq} / \mathrm{m}^{3}$ to WLM was performed based on an assumption of $2000 \mathrm{~h}$ of work per year, leading to a correspondence of $1 \mathrm{~Bq} / \mathrm{m}^{3}$ to $0.00126 \mathrm{WLM}$ (ICRP 1993). Total cumulative exposure and time since last exposure information was calculated from average job durations, which were estimated by occupation, sex, and age group using data from the lifetime job histories of controls in the National Enhanced Cancer Surveillance System (Johnson 1998).

\section{Results}

Approximately 26,000 high-risk workers and 15.5 million indoor workers were exposed to radon during the REP (Table 1). The majority of exposed indoor workers (79\%) were in the lowest exposure group with an exposure level of $>0-50 \mathrm{~Bq} / \mathrm{m}^{3}$. Very few exposed workers $(0.5 \%)$ in indoor workplaces had exposures above $400 \mathrm{~Bq} / \mathrm{m}^{3}$. The lung cancer attributable fraction and number of cases for indoor workers by Canadian province are shown in Table 2 .

Average lung cancer relative risk for the high-risk workers was 1.60. Average cancer risks for the indoor workers were 1.01 and 1.42 for the lowest and highest exposed groups, respectively.

The fraction of lung cancers attributable to radon exposure among high-risk workers was $0.07 \%(95 \% \mathrm{CI}=0.05-0.25 \%)$, which equated to approximately 16 new cancer cases in 2011. These cancers occurred almost completely (98\%) in underground mining and oil and gas extraction industries. The remaining percentages of lung cancers occurred in workers from transportation/warehousing industries (1.2\%) 
Table 1 Lung cancer cases attributable to occupational radon exposure by exposure level. Results presented as both number of cases and attributable fraction of cases

\begin{tabular}{lllll}
\hline & $\begin{array}{l}\text { Exposure } \\
\text { level (Bq/ } \\
\left.\mathrm{m}^{3}\right)\end{array}$ & NeREP $(\% \text { of total exposed })^{\mathrm{a}}$ & $\begin{array}{l}\text { Attributable lung } \\
\text { cancers } \\
\text { cases })\end{array}$ & $\begin{array}{l}\text { Population attrib- } \\
\text { utable fraction (\%) }\end{array}$ \\
\hline Indoor workers & $>0-50$ & $12,284,327(79 \%)$ & $74(39 \%)$ & 0.31 \\
& $>50-100$ & $1,979,557(13 \%)$ & $36(19 \%)$ & 0.15 \\
& $>100-150$ & $604,486(4 \%)$ & $18(10 \%)$ & 0.08 \\
& $>150-200$ & $254,953(2 \%)$ & $11(6 \%)$ & 0.05 \\
& $>200-400$ & $272,887(2 \%)$ & $20(10 \%)$ & 0.08 \\
& $>400-800$ & $65,678(0.4 \%)$ & $9(5 \%)$ & 0.04 \\
& $>800$ & $14,109(0.2 \%)$ & $5(3 \%)$ & 0.02 \\
High-risk workers & $>800$ & $26,109(0.2 \%)$ & $16(9 \%)$ & 0.07 \\
& Total & $15,502,892(100 \%)$ & $188(100 \%)$ & 0.80 \\
\hline
\end{tabular}

${ }^{a}$ Number of cases may not add up to total because of rounding

\begin{tabular}{llll}
\hline Province & NeREP $(\% \text { of total exposed })^{\mathrm{a}}$ & $\begin{array}{l}\text { Attributable lung } \\
\text { cancers }^{\mathrm{a}} \\
(\% \text { of total cases })\end{array}$ & $\begin{array}{l}\text { Attributable fraction (\% } \\
\text { of total cases in region) }\end{array}$ \\
\hline Alberta & $1,639,001(10.6 \%)$ & $18(10.6 \%)$ & 0.99 \\
British Columbia & $1,766,097(11.4 \%)$ & $14(8.4 \%)$ & 0.52 \\
Manitoba & $608,106(3.9 \%)$ & $15(8.6 \%)$ & 1.73 \\
New Brunswick & $344,117(2.2 \%)$ & $4(2.3 \%)$ & 0.61 \\
Newfoundland & $236,514(1.5 \%)$ & $3(1.6 \%)$ & 0.71 \\
Nova Scotia & $459,550(3.0 \%)$ & $5(2.8 \%)$ & 0.54 \\
Ontario & $6,117,923(39.5 \%)$ & $48(28.2 \%)$ & 0.60 \\
Prince Edward Island & $57,922(0.4 \%)$ & $1(0.3 \%)$ & 0.38 \\
Quebec & $3,744,181(24.2 \%)$ & $49(28.4 \%)$ & 0.68 \\
Saskatchewan & $503,372(3.3 \%)$ & $15(8.7 \%)$ & 1.94 \\
Total & $15,476,783(100 \%)$ & $172(100 \%)$ & 0.73 \\
\hline
\end{tabular}

${ }^{a}$ Number of cases may not add up to total because of rounding
Table 2 Number and fraction of cancers attributable to occupational radon exposure for indoor workers by the included Canadian province improved methods to estimate the occupational contribution to radon-induced lung cancers. The majority of indoor workers were exposed to relatively low levels of radon in the workplace.

Our results show that exposure above $200 \mathrm{~Bq} / \mathrm{m}^{3}$, the current Health Canada guideline for intervention, is estimated to account for $20 \%$ of the attributable lung cancer cases associated with indoor exposures. If the limit is further lowered to $100 \mathrm{~Bq} / \mathrm{m}^{3}, 37 \%$ of the cases could be prevented. Our estimates are similar with those from the UK Burden Study, where the authors noted that around $10 \%$ of all radon-attributable lung cancers are avoidable because most attributable cases were associated with radon exposures below $200 \mathrm{~Bq} /$ $\mathrm{m}^{3}$ (Brown et al. 2012a). An analysis of residential radon exposure in Canada found that remediating homes above the Health Canada guideline of $200 \mathrm{~Bq} / \mathrm{m}^{3}$ down to background levels $\left(10-30 \mathrm{~Bq} / \mathrm{m}^{3}\right)$ would prevent $28 \%$ of radon-attributable lung cancer deaths (Peterson et al. 2013). Slightly over half $(52 \%)$ of the radon-attributable lung cancer deaths 
would require remediation of all homes above $50 \mathrm{~Bq} / \mathrm{m}^{3}$ (Chen et al. 2012). Radon exposure awareness and building remediation initiatives in regions with high geologic potential for radon emission may have the benefit of reducing both the occupational and residential burden of radon-related lung cancer.

Our study included detailed and quantitative radon exposure estimates for Canadian workers by job, industry, and geographical region. Exposures for indoor workers, where over $90 \%$ of radon-attributable cases occurred, were modeled with more than 12,000 workplace radon measurements collected in workplaces across Canada. Various registries, including the Canadian national census, Labour Force Survey, and National Enhanced Cancer Surveillance System were also linked to fully characterize the Canadian workforce in detail. There are, however, several limitations in our work. Data collection for the workplace radon measurements were carried out year-round in air-conditioned buildings and in the fall/winter in buildings with natural ventilation. However, building ventilation information was not available in our dataset and we were unable to calculate the ratio of the two building types or perform sensitivity analysis using radon measurements from air-conditioned buildings only. The fall/winter measurements may overestimate average annual radon concentrations in buildings with natural ventilation, leading to overestimation of attributable risk in indoor workers. However, a recent study based on Canadian residential radon measurements suggested that no seasonal adjustments are needed for radon concentrations in population-level studies because radon levels were not found to be consistently higher in the majority of homes in winter (Stanley et al. 2019). We were also unable to account for historical changes in radon exposure. There is evidence that newer Canadian homes tended to have higher radon concentration compared to older homes (Stanley et al. 2019). If the same applies to workplace buildings, then past exposure may have been overestimated in our study, leading to an overestimation of attributable risk and cases. For high-risk underground workers, assuming a constant exposure likely underestimated past exposures and, therefore, attributable cancer cases.

In addition to being the leading cause of lung cancer, cigarette smoking also acts synergistically with radon exposure in causing lung cancer (Leuraud et al. 2011; National Research Council (US) Committee on Health Risks of Exposure to Radon 1999). However, smoking data was not available for our population. The BEIR VI standard exposure-age-concentration model also did not account for smoking status. In combining the BEIR VI model-derived risks with overall rates of lung cancer among both smokers and non-smokers for our attribute risk calculations, we assumed a constant ratio of excess risk for smokers and non-smokers, which is consistent with a multiplicative model interaction between radon exposure and smoking (National Research Council (US) Committee on Health Risks of Exposure to Radon 1999). There are, however, suggestions that the interaction between smoking and radon may be super-additive but sub-multiplicative (Leuraud et al. 2011; National Research Council (US) Committee on Health Risks of Exposure to Radon 1999). If this were true, our results would overestimate the risk for smokers and underestimate the risk for non-smokers, leading to an overestimate of overall risk because radon-related lung cancer burden is much higher in smokers than in non-smokers (Mendez et al. 2011; National Research Council (US) Committee on Health Risks of Exposure to Radon 1999).

In summary, our work showed a small lung cancer burden associated with occupational radon exposure and most of the burden occurred among workers exposed at relatively low levels of radon in indoor workplaces. A combination of smoking cessation strategies with identification and remediation of workplaces with high radon concentrations, particularly in regions with high underlying geological potential for radon emission, may help reduce this burden.

Funding Funding of the study was provided by the Canadian Cancer Society Multi-Sector Team Grant in Prevention Research (\#701285). Additional funding support was provided by Cancer Care Ontario, the Ontario Ministry of Labour, the Canadian Cancer Society, WorkSafeBC, the Canadian Partnership Against Cancer, and the Canadian Institutes of Health Research.

\section{Compliance with ethical standards}

Conflict of interest The authors declare no potential conflict of interest.

Open Access This article is licensed under a Creative Commons Attribution 4.0 International License, which permits use, sharing, adaptation, distribution and reproduction in any medium or format, as long as you give appropriate credit to the original author(s) and the source, provide a link to the Creative Commons licence, and indicate if changes were made. The images or other third party material in this article are included in the article's Creative Commons licence, unless indicated otherwise in a credit line to the material. If material is not included in the article's Creative Commons licence and your intended use is not permitted by statutory regulation or exceeds the permitted use, you will need to obtain permission directly from the copyright holder. To view a copy of this licence, visit http://creativecommons.org/licenses/by/4.0/.

\section{References}

Agency for Toxic Substances and Disease Registry (ATSDR) (2012) Toxicological profile for radon. US Department of Health and Human Services, Public Health Services Atlanta, GA

Al-Arydah M (2017) Population attributable risk associated with lung cancer induced by residential radon in Canada: sensitivity to relative risk model and radon probability density function choices: In memory of Professor Jan M. Zielinski. Sci Total Environ 596-597:331-341. https://doi.org/10.1016/j.scitotenv.2017.04.067 
Beaugrand S, Sutton L (2012) Vibration, confined space, and little leeway for improvement-addressing the challenges posed by the Montreal subway operator workstation Institut de recherche Robert-Sauve en sante et en securite du travail Montreal

Bissett RJ, McLaughlin JR (2010) Radon. Chronic Dis Can 29(Suppl 1):38-50

Brown T, Cherrie J, Fortunato L (2012a) The burden of occupational cancer in Great Britain: lung cancer. Health and Safety Executive London

Brown T, Darnton A, Fortunato L, Rushton L, British Occupational Cancer Burden Study G (2012b) Occupational cancer in Britain. Respiratory cancer sites: larynx, lung and mesothelioma. Br J Cancer 107(Suppl 1):S56-70. https://doi.org/10.1038/bjc.2012.119

Chen J, Ford KL (2017) A study on the correlation between soil radon potential and average indoor radon potential in Canadian cities. J Environ Radioact 166:152-156. https://doi.org/10.1016/j.jenvr ad.2016.01.018

Chen J, Moir D, Whyte J (2012) Canadian population risk of radon induced lung cancer: a re-assessment based on the recent crossCanada radon survey. Radiat Prot Dosimetry 152:9-13. https:// doi.org/10.1093/rpd/ncs147

Canadian Broadcast Corporation (CBC) (2014) Dorion fish hatchery radon gas levels prompt work refusal. CBC News. https://www. cbc.ca/news/canada/thunder-bay/dorion-fish-hatchery-radon-gaslevels-prompt-work-refusal-1.2866289. Accessed 6 Mar 2020

Gogna P et al (2019) Estimates of the current and future burden of lung cancer attributable to residential radon exposure in Canada. Prev Med 122:100-108. https://doi.org/10.1016/j.ypmed.2019.04.005

Health Canada (2014) Radon testing in federal buildings-highlights. Health Canada

Health Canada (2019) National dose registry. Government of Canada. https://www.canada.ca/en/health-canada/services/environmentalworkplace-health/occupational-health-safety/occupational-radia tion/national-dose-registry.html. Accessed 6 Mar 2020

Howe GR, Stager RH (1996) Risk of lung cancer mortality after exposure to radon decay products in the Beaverlodge cohort based on revised exposure estimates. Radiat Res 146:37-42

Howe GR, Nair RC, Newcombe HB, Miller AB, Abbatt JD (1986) Lung cancer mortality (1950-80) in relation to radon daughter exposure in a cohort of workers at the Eldorado Beaverlodge uranium mine. J Natl Cancer Inst 77:357-362

Howe GR, Nair RC, Newcombe HB, Miller AB, Burch JD, Abbatt JD (1987) Lung cancer mortality (1950-80) in relation to radon daughter exposure in a cohort of workers at the Eldorado Port Radium uranium mine: possible modification of risk by exposure rate. J Natl Cancer Inst 79:1255-1260

IARC Working Group on the Evaluation of Carcinogenic Risks to Humans (2009) A review of human carcinogens. Part D:Radiation. International Agency for Research on Cancer, Lyon

ICRP (1993) Protection against Radon-222 at home and at work, vol 23. International Commission on Radiological Protection Ottawa, ON

Johnson KC (1998) The National Enhanced Cancer Surveillance System: a case-control approach to environment-related cancer surveillance in Canada. Environmetrics 9:495-504. https://doi. org/10.1002/(ISSN)1099-095X

Kalinowski T (2014) Driverless subway trains? Not in nervous Toronto, says TTC head. Toronto

Kim J et al (2018) Burden of lung cancer attributable to occupational diesel engine exhaust exposure in Canada. Occup Environ Med 75:617-622. https://doi.org/10.1136/oemed-2017-104950

Labreche F et al (2019) The current burden of cancer attributable to occupational exposures in Canada. Prev Med 122:128-139. https ://doi.org/10.1016/j.ypmed.2019.03.016

Leuraud K et al (2011) Radon, smoking and lung cancer risk: results of a joint analysis of three European case-control studies among uranium miners. Radiat Res 176:375-387
Marsh JW, Laurier D, Tirmarche M (2017) Radon dosimetry for workers: ICRP's approach. Radiat Protect Dosimetry 177:466-474. https://doi.org/10.1093/rpd/ncx065

Mendez D, Alshanqeety O, Warner KE, Lantz PM, Courant PN (2011) The impact of declining smoking on radon-related lung cancer in the United States. Am J Public Health 101:310-314. https://doi. org/10.2105/AJPH.2009.189225

National Research Council (US) Committee on Health Risks of Exposure to Radon (1999) Models and risk projections. In: Health effects of exposure to radon: BEIR VI. Washington (DC). doi: $10.17226 / 5499$

National Toxicology Program (2015) Report on carcinogens: thirteenth edition US Department of Health and Human Services, Public Health Services, Research Triangle Park, NC

Navaranjan G, Berriault C, Do M, Villeneuve PJ, Demers PA (2016) Cancer incidence and mortality from exposure to radon progeny among Ontario uranium miners. Occup Environ Med 73:838-845. https://doi.org/10.1136/oemed-2016-103836

NRPB (2000) Health risks from radon. National Radiological Protection Board, Chilton

Peters CE, Ge CB, Hall AL, Davies HW, Demers PA (2015) CAREX Canada: an enhanced model for assessing occupational carcinogen exposure. Occup Environ Med 72:64-71. https://doi.org/10.1136/ oemed-2014-102286

Peterson E, Aker A, Kim J, Li Y, Brand K, Copes R (2013) Lung cancer risk from radon in Ontario, Canada: how many lung cancers can we prevent? Cancer Causes Control 24:2013-2020. https://doi. org/10.1007/s10552-013-0278-x

Samet JM (1989) Radon and lung cancer. J Natl Cancer Inst 81:745757. https://doi.org/10.1093/jnci/81.10.745

Stanley FK, Zarezadeh S, Dumais CD, Dumais K, MacQueen R, Clement F, Goodarzi AA (2017) Comprehensive survey of household radon gas levels and risk factors in southern Alberta. CMAJ Open 5:E255-E264. https://doi.org/10.9778/cmajo.20160142

Stanley FK, Irvine JL, Jacques WR, Salgia SR, Innes DG, Winquist BD, Torr D, Brenner DR, Goodarzi AA (2019) Radon exposure is rising steadily within the modern North American residential environment, and is increasingly uniform across seasons. Sci Rep 9:1-17. https://doi.org/10.1038/s41598-019-54891-8

Statistics Canada Canadian Cancer Registry (CCR). Statistics Canada, Ottawa, ON

Statistics Canada (1976-2003) Labour force survey (microdata files). Ottawa, ON

Statistics Canada Demography Division (1960-2002) Life tables, Canada, provinces and territories. Statistics Canada, Ottawa, ON

Steenland K, Burnett C, Lalich N, Ward E, Hurrell J (2003) Dying for work: the magnitude of US mortality from selected causes of death associated with occupation. Am J Ind Med 43:461-482. https://doi.org/10.1002/ajim.10216

Torres-Duran M, Barros-Dios JM, Fernandez-Villar A, Ruano-Ravina A (2014) Residential radon and lung cancer in never smokers. A systematic review. Cancer Lett 345:21-26. https://doi. org/10.1016/j.canlet.2013.12.010

U.S. Department of Health and Human Services (1987) Radon progeny in underground mines. National Institute for Occupational Health and Safety, Washington, DC

Whyte J, Falcomer R, Chen J (2019) A comparative study of radon levels in federal buildings and residential homes in Canada. Health Phys 117:242-247. https://doi.org/10.1097/HP.0000000000001057

World Health Organization (2009) WHO handbook on indoor radon: a public health perspective. World Health Organization, Geneva

Publisher's Note Springer Nature remains neutral with regard to jurisdictional claims in published maps and institutional affiliations. 